\title{
EFEITO DE BACTÉRIAS DIAZOTRÓFICAS NA PRODUÇÃO DE ABACAXIZEIRO “CAYENNE CHAMPAC", SOB IRRIGAÇÃO, EM DOIS NÍVEIS DE ADUBAÇÃO NITROGENADA ${ }^{1}$
}

\author{
OLMAR BALLER WEBER ${ }^{2}$, DANIEL TERAO ${ }^{3}$, LETO SARAIVA ROCHA ${ }^{4}$, DIVA CORREIA ${ }^{5}$, \\ FRANCISCO JOSÉ DE SEIXAS SANTOS ${ }^{6}$
}

\begin{abstract}
RESUMO - Avaliou-se o efeito de bactérias diazotróficas na produção de abacaxizeiro cv. Cayenne Champac (Champaka), sob irrigação, em dois níveis de adubação nitrogenada. Os tratamentos constaram dos níveis de $\mathrm{N}$ de $180 \mathrm{~kg} \mathrm{ha}^{-1}$ ano ${ }^{-1}$ e $300 \mathrm{~kg} \mathrm{ha}^{-1}$ ano $^{-1}$, nas parcelas e subparcelas de mudas micropropagadas inoculadas com bactéria relacionada a Burkholderia cepacia AB213, de bactéria Asaia bogorensis AB219 e controles sem inoculação bacteriana, utilizando-se de três repetições. A inoculação bacteriana foi realizada no laboratório $\left(10^{8}\right.$ células planta $\left.{ }^{-1}\right)$ e a aclimatação das mudas, em casa de vegetação. Após 5 meses, as mudas foram transplantadas no campo, utilizando-se de $0,9 \mathrm{~m}$ entre as linhas e $0,3 \mathrm{~m}$ entre as plantas. A cultivar apresentou bom desempenho sob irrigação no solo arenoso de Pacajus, Estado do Ceará, quando adubado com o maior nível de N. Para cada quilograma do elemento fornecido, houve incremento de $124,3 \mathrm{~kg} \mathrm{ha}^{-1}$ na massa fresca dos frutos com coroa, entre os níveis da adubação nitrogenada. Na dose maior de N, plantas inoculadas do AB219 produziram frutos maiores e massas frescas 19,4\% e 17,3\% superiores aos controles, respectivamente, para frutos sem e com coroa. O efeito do AB213 na produção foi menor $(9,9 \%)$ no nível mais baixo de N. A evidência do efeito de bactérias diazotróficas na cultivar Cayenne Champac foi demonstrada.
\end{abstract}

Termos para indexação: Ananas comosus L., mudas micropropagadas, bactéria diazotrófica, Burkholderia sp., Asaia bogorensis.

\section{CONTRIBUTION OF DIAZOTROPHIC BACTERIA ON YIELD OF PINEAPPLE 'CAYENNE CHAMPAC’, UNDER IRRIGATION, WITH TWO LEVELS OF NITROGEN FERTILIZATION}

\begin{abstract}
The objective of this work was to evaluate the effect of diazotrophic bacteria on yield of pineapple cv. Cayenne Champac (Champaka), under irrigation, with two levels of $\mathrm{N}$ fertilization. Treatments consisted of two N levels ( $180 \mathrm{~kg}$ and $300 \mathrm{~kg} \mathrm{ha}^{-1}$ year ${ }^{-1}$ ), on the plots, and micropropagated plantlets inoculated with bacteria related to Burkholderia cepacia AB213, with Asaia bogorensis AB219 and without bacterial inoculation, on the subplots, using three replications. The bacterial inoculation was performed in a laboratory (with $10^{8}$ bacterial cells plant ${ }^{-1}$ ) and the plant acclimatization in a glass house. After five months, they were transferred onto field, using $0.9 \mathrm{~m}$ between the lines and $0.3 \mathrm{~m}$ between the plants. The cultivar presented good performance under irrigation on the sandy soil in Pacajús, Ceará State, when fertilized with the highest N level. For each kilogram of the element the fresh mass of fruits grew by $124.3 \mathrm{~kg} \mathrm{ha}^{-1}$, for the fertilizer levels. Plants inoculated with AB219 produced bigger fruits and $19.4 \%$ and $17.3 \%$ heavier when compared to fresh mass of fruits without and with crown from the controls on higher N level. The lower contribution of AB213 isolate was observed, and the fresh mass of fruits with crown ranged up to $9.9 \%$ on lower $\mathrm{N}$ level. The diazotrophic bacterial contribution on pineapple cv. Cayenne Champac was demonstrated with this work..
\end{abstract}

Index terms: Ananas comosus L., micropropagated plant, diazotrophic bacteria, Burkholderia sp., Asaia bogorensis.

\section{INTRODUÇÃO}

O abacaxizeiro é cultivado em mais de 70 países, e o Brasil ocupa o terceiro lugar na produção de abacaxi, superado pela Tailândia e Filipinas (FAO, 2003). A cultura pode ser encontrada nas diferentes regiões do País, porém, em área de cultivo, destaca-se o Nordeste. Nesta região, são colhidos mais de 25 mil hectares da cultura a cada ano (Agrianual, 2002) apesar da baixa produtividade (45 $\mathrm{t} \mathrm{ha}^{-1}$ de abacaxi) decorrente do nível tecnológico adotado pelos produtores na região.

As mudas são obtidas diretamente no campo, possibilitando a disseminação de doenças e pragas. Este fato é agravado pelos poucos genótipos plantados, prevalecendo as cultivares Pérola e Smooth Cayenne, não diferenciando das demais regiões produtoras no País. Segundo Reinhardt \& Souza (2000), a cultivar Pérola representa cerca de $80 \%$ da produção nacional. Adicionalmente, tem-se elevada suscetibilidade a doenças como fusariose (Spironello et al., 1997a, b), causado pelo Fusarium subglutinans (Santos et al., 2002), podendo causar perdas expressivas na produção de abacaxi.

A micropropagação representa uma alternativa na obtenção de mudas de abacaxizeiro (Teixeira et al., 2001; Firoozabady \& Gutterson, 2003), sobretudo quando se trata de genótipos pouco plantados e sensíveis a doenças. Porém, na multiplicação in vitro, quando se retiram patógenos, podem-se também eliminar outros microrganismos que beneficiam a cultura. A retirada destes agentes poderia tornar as plantas mais sensíveis aos patógenos.

Entre os microrganismos benéficos, citam-se as bactérias diazotróficas, recentemente isoladas do abacaxizeiro (Weber et al., 1999; Tapia-Hernández et al., 2000) e de outras culturas (Reis et al., 2000). O restabelecimento da associação com isolados dessas bactérias em mudas micropropagadas favoreceu o crescimento e a sobrevivência de plântulas do abacaxizeiro, durante a fase de aclimatação (Weber et al., 2003a, b). Essa associação simbiótica resulta na fixação biológica de $\mathrm{N}_{2}$ em canade-açúcar (Boddey et al., 2003), arroz (Baldani et al., 2000) e outras gramíneas (Reis et al., 2000; Dobbelaere et al., 2003). Este processo também não pode ser descartado na cultura do abacaxizeiro, principalmente em regiões de baixa fertilidade natural.

Convém salientar que áreas ocupadas pela cultura no Nordeste apresentam solos arenosos e pobres em nutrientes. De outro modo, o abacaxizeiro é considerado exigente em nutrientes, principalmente nos elementos NPK. Souza (1999) relatou que adubações da cultura no Brasil variavam de 6 a $10 \mathrm{~g}_{\text {planta }}{ }^{-1}$ de $\mathrm{N}, 1$ a $4 \mathrm{~g} \mathrm{planta}^{-1}$ de $_{2} \mathrm{O}_{5}$ e 4 a $15 \mathrm{~g}_{\text {planta- }}$ ${ }^{1} \mathrm{de}_{2} \mathrm{O}$. Dosagens mais altas dos nutrientes têm sido aplicadas, podendo chegar a 19,2 $\mathrm{g}$ de $\mathrm{Ne}$ de $\mathrm{K}_{2} \mathrm{O}$ e 4,8g de $\mathrm{P}_{2} \mathrm{O}_{5}$ (Spironello \& Furlani, 1997) e 22 g planta $^{-1}$ de $_{2} \mathrm{O}$ (Veloso et al., 2001).

Em áreas de expansão da cultura, como ocorre nos agropólos do Estado do Ceará (SEAGRI-CE, 2003), verifica-se interesse dos

\footnotetext{
${ }^{1}$ (Trabalho 180/2003). Recebido: 04/12/2003. Aceito para publicação: 02/08/2004.

${ }^{2}$ Agrônomo, D.Sc., Embrapa Agroindústria Tropical, Rua Dra. Sara Mesquita, 2270, Planalto Pici, CEP60511-110, Fortaleza, CE. Fone (85) 299-1800 E-mail: weber@cnpat.embrapa.br

${ }^{3}$ Agrônomo, D.Sc., Embrapa Agroindústria Tropical, E-mail: daniel@ cnpat.embrapa.br

${ }^{4}$ Técnico, Embrapa Agroindústria Tropical. E-mail: leto@cnpat.embrapa.br

${ }^{5}$ Bióloga, M.Sc., Embrapa Agroindústria Tropical. E-mail: diva@ cnpat.embrapa.br

${ }^{6}$ Agrônomo, M.Sc., Embrapa Meio Norte, Av. Duque de Caxias, 5650, Buenos Aires, CEP64006-220, Terezina, PI. Fone (86) 225-1141 E-mail: seixas@ cpamn.embrapa.br
} 
TABELA 1 - Valores médios de temperatura, insolação e precipitação mensais observados durante o período de condução do experimento com abacaxizeiro 'Cayenne Champac', em Pacajus (CE).

\begin{tabular}{|c|c|c|c|c|c|c|c|c|c|}
\hline \multirow[t]{2}{*}{ Meses } & \multicolumn{3}{|c|}{ Temperatura média $\left(\mathrm{C}^{\circ}\right)$} & \multicolumn{3}{|c|}{ Insolação (h) } & \multicolumn{3}{|c|}{ Precipitação (mm) } \\
\hline & 2000 & 2001 & 2002 & 2000 & 2001 & 2002 & 2000 & 2001 & 2002 \\
\hline Janeiro & - & 27,2 & 20,7 & - & 224,5 & 159,1 & - & 128,2 & 268,4 \\
\hline Fevereiro & - & 27,3 & 23,9 & - & 223,3 & 232,4 & - & 53,5 & 52,5 \\
\hline Março & - & 27,0 & 26,7 & - & 164,8 & 122,9 & - & 123,3 & 347,8 \\
\hline Abril & - & 25,9 & 25,6 & - & 37,9 & 186,0 & - & 460,0 & 310,9 \\
\hline Maio & - & 26,2 & 26,1 & - & 269,3 & 239,3 & - & 55,8 & 216,2 \\
\hline Junho & - & 25,9 & 25,8 & - & 249,0 & 148,3 & - & 76,3 & 61,3 \\
\hline Julho & - & 26,0 & 26,0 & - & 311,6 & 305,3 & - & 86,0 & 37,3 \\
\hline Agosto & - & 26,1 & 27,0 & - & 330,2 & 321,2 & - & 0,1 & 0 \\
\hline Setembro & - & 26,9 & 26,5 & - & 238,4 & 308,4 & - & 6,0 & 0 \\
\hline Outubro & - & 26,9 & 27,8 & - & 279,6 & 328,8 & - & 8,2 & 11,5 \\
\hline Novembro & 26,3 & 27,1 & - & 282,1 & 282,1 & - & 9,8 & 8,5 & - \\
\hline Dezembro & 26,5 & 23,6 & - & 280,0 & 280,0 & - & 11,0 & 35,7 & - \\
\hline
\end{tabular}

Fonte: Dados fornecidos pela FUNCEME (Fundação Cearense de Meteorologia e Recursos Hídricos), em fortaleza-CE.

produtores por cultivares como Cayenne Champac, cujos frutos se destinam à exportação. Porém, nesta cultivar, verifica-se pouca disponibilidade de mudas. A micropropagação poderia aumentar o número dessas plantas e favorecer a redução de patógenos.

Este trabalho teve por objetivo avaliar o efeito de bactérias diazotróficas inoculadas em plantas micropropagadas do abacaxizeiro, cultivar Cayenne Champac, sob irrigação, em dois níveis de adubação nitrogenada.

\section{MATERIALEMÉTODOS}

O experimento com abacaxizeiro (Ananas comosus $(\mathrm{L})$ Merril) $\mathrm{cv}$. Cayenne Champac (Champaka) constou dos níveis de $\mathrm{N}$ de $180 \mathrm{~kg} \mathrm{ha}^{-1}$ ano $^{-1}$ e $300 \mathrm{~kg} \mathrm{ha}^{-1}$ ano $^{-1}$ aplicados como uréia, nas parcelas; as mudas inoculadas ou não com bactéria relacionada a Burkholderia cepacia $\mathrm{AB} 213$ e a Asaia bogorensis AB219) foram alocadas nas subparcelas de cada tratamento (parcela) com nitrogênio. Os tratamentos das subparcelas foram casualizados, utilizando-se de três repetições e 20 plantas (12 plantas úteis) em cada. $\mathrm{O}$ experimento foi conduzido no campo experimental da Embrapa Agroindústria Tropical, em Pacajus-CE, de novembro de 2000 a outubro de 2002. As médias mensais de temperatura do ar, insolação e precipitação durante o período podem ser observadas na Tabela 1 .

As mudas foram obtidas a partir de gemas axilares. Durante a micropropagação, os explantes foram repicados até cinco vezes, no meio MS (Murashige \& Skoog, 1962) suplementado com 0,5 mg L-1 de 6benzilamino purina, $0,5 \mathrm{mg} \mathrm{L}^{-1}$ de ácido naftaleno-acético e agarizado $(5 \mathrm{~g}$ $\left.\mathrm{L}^{-1}\right)$. Após o enraizamento in vitro, utilizando o meio MS agarizado sem os reguladores, plântulas com 8 a $10 \mathrm{~cm}$ de comprimento das folhas e cerca de $1,9 \mathrm{~g}$ de massa fresca foram transferidas para frascos de vidro transparentes com capacidade de $250 \mathrm{~mL}$, onde foram colocadas em contato com suspensões de isolados bacterianos $\left(10^{8}\right.$ células por planta), conforme Weber et al. (2003b). As bactérias utilizadas eram oriundas de plantas adultas da cultivar Pérola e foram identificadas com base em sequiências dos genes 16S rDNA (Weber et al., 2003a, b). Após dois dias em contato com as bactérias nos frascos, as plantas foram transferidas para tubetes, contendo $188 \mathrm{~mL}$ de uma mistura autoclavada de areia, vermiculita e vermicomposto (proporção 1:1:1, v/v), em casa de vegetação, onde foram aclimatadas durante 5 meses, de acordo com Weber et al. (2003b), para posterior transplantio no campo.

O solo da área foi previamente analisado (Silva, 1999), apresentando, na camada de 0 a $20 \mathrm{~cm}$ de profundidade, as seguintes características: $\mathrm{pHem} \mathrm{CaCl}_{2} 0,001 \mathrm{M}=4,9 ;$ matéria orgânica $(\mathrm{MO})=15 \mathrm{mg}$ / $\mathrm{dm}^{3} ; \mathrm{P}$ resina $=14 \mathrm{mg} / \mathrm{dm}^{3} ; \mathrm{K}=1,6 \mathrm{mmol}_{\mathrm{c}} / \mathrm{dm}^{3} ; \mathrm{Ca}=11 \mathrm{mmol} / \mathrm{dm}^{3} ; \mathrm{Mg}=9$ $\mathrm{mmol} / \mathrm{dm}^{3} ; \mathrm{Na}=0,3 \mathrm{mmol} / \mathrm{dm}^{3} ; \mathrm{Cu}=2,2 \mathrm{mg} / \mathrm{dm}^{3} ; \mathrm{Fe}=30,3 \mathrm{mg} / \mathrm{dm}^{3} ; \mathrm{Mn}=$ $15,6 \mathrm{mg} / \mathrm{dm}^{3} ; \mathrm{Zn}=0,9 \mathrm{mg} / \mathrm{dm}^{3} ;$ soma de bases $=39,4 \mathrm{mmol} / \mathrm{dm}^{3} ;$ capacidade de troca de cátions $=24,1 \mathrm{mmol} / \mathrm{dm}^{3}$, e saturação de bases $=23 \%$.

Após preparo da área, marcaram-se filas de $0,9 \mathrm{~m}$ e abriram-se covas na profundidade de $15 \mathrm{~cm}$ a cada $0,3 \mathrm{~m}$ ao longo das filas. $\mathrm{Na}$ adubação de base, aplicaram-se o superfosfato simples $\left(80 \mathrm{~kg} \mathrm{ha}^{-1} \mathrm{de}\right.$ $\mathrm{P}_{2} \mathrm{O}_{5}$ ) e o óxido silicatado na dose de $50 \mathrm{~kg} \mathrm{ha}^{-1}$ [4,6 kg de $\mathrm{Zn}(9,2 \%), 1,1$ $\mathrm{kg}$ de $\mathrm{B}(2,2 \%), 0,4 \mathrm{~kg}$ de $\mathrm{Cu}(0,8 \%), 1,85 \mathrm{~kg}$ de $\mathrm{Fe}(3,7 \%), 1,7 \mathrm{~kg}$ de $\mathrm{Mn}$ $(3,4 \%)$ e $0,05 \mathrm{~kg}$ de $\mathrm{Mo}(0,1 \%)]$. A adubação de cobertura com a uréia, como fonte de N, e o cloreto de potássio $\left(400 \mathrm{~kg} \cdot \mathrm{ha}^{-1} \mathrm{ano}^{-1}\right.$ de $\left.\mathrm{K}_{2} \mathrm{O}\right)$, foi feita a cada 3 meses, durante um ano e meio. Aos 12 meses repetiu-se a aplicação da dose com o adubo silicatado contendo micronutrientes. As doses de $300 \mathrm{~kg} \mathrm{ha}^{-1}$ de $\mathrm{N}, \mathrm{P}_{2} \mathrm{O}_{5}$ e $\mathrm{K}_{2} \mathrm{O}$ foram calculadas baseadas na recomendação de adubação de Spironello \& Furlani (1997), visando à produtividade de $40 \mathrm{t} \mathrm{ha}^{-1}$ de frutos (Spironello \& Furlani, 1997). A dose dos micronutrientes à base de óxidos silicatados foi utilizada de acordo com as recomendações de Souza (1999).

Após o plantio no campo e a adubação em cobertura, as mudas foram irrigadas utilizando-se do sistema de microaspersão, fornecendose cerca de 7,5 $\mathrm{L} \mathrm{dia}^{-1} \mathrm{~m}^{2}$ (aspersores fornecendo $40 \mathrm{~L} \mathrm{~h}^{-1} \mathrm{e}$ cobrindo área com diâmetro de 4,5 m), em dias ensolarados. Procurou-se manter a área livre de plantas invasoras, mediante capinas mecânicas e manuais.

Aos 14 meses, quando algumas plantas já possuíam frutos, aplicou-se 1 a 3 g planta $^{-1}$ de carbureto de cálcio na roseta das plantas que não estavam com inflorescência, na parcela que recebeu maior dose de N. Nas plantas adubadas com a dose menor do adubo nitrogenado, aplicou-se o tratamento de indução floral três meses após, quando começaram a surgir inflorescências na parcela.

Por ocasião da colheita, aos 18 meses, mediram-se o comprimento e o diâmetro médio dos abacaxis e determinou-se a massa fresca dos frutos com e sem coroa. Os frutos foram categorizados em tipo A $(>1,5 \mathrm{~kg}), \mathrm{B}(1,2 \mathrm{~kg}$ a $1,5 \mathrm{~kg})$ e C $(<1,2 \mathrm{~kg})$, conforme Santana et al. (2001), e calculando-se a produtividade $\left(\mathrm{t} \mathrm{ha}^{-1}\right)$. Mediu-se também, nessa ocasião, o comprimento das folhas medianas de todas as plantas, e coletaram-se amostras de raízes frescas e segmentos do caule (abaixo do fruto) de três plantas por repetição. Essas amostras frescas foram esterilizadas superficialmente com cloramina $\mathrm{T}$ a $1 \%$, durante $5 \mathrm{~min}$, lavadas e estabilizadas em solução tampão $\left(50 \mathrm{mM}\right.$ de $\left.\mathrm{H}_{2} \mathrm{PO}_{4}, \mathrm{em} \mathrm{pH} 7,0\right)$, maceradas, diluídas e inoculadas em frascos com meio semi-sólido JNFb, para a avaliação do crescimento e determinação da contagem do número mais provável (NMP) de bactérias diazotróficas endofíticas (Döbereiner et al., 1995).

Os dados das características de crescimento e de produção do abacaxizeiro foram submetidos à análise de variância, utilizando-se do módulo GLM (General Linear Models) do SAS System. O efeito do tipo de muda dentro dos níveis de $\mathrm{N}$ foi avaliado, utilizando-se de testes $\mathrm{t}$ para os contrastes entre médias dos tratamentos (Montgomery, 1991).

\section{RESULTADOSE DISCUSSÃO}

O abacaxizeiro micropropagado da cultivar Cayenne Champac teve bom desempenho quando foi adubado com a dose completa de $\mathrm{N}$ $\left(8,1 \mathrm{~g} \mathrm{planta}^{-1}\right.$ ano $\left.^{-1}\right), \mathrm{P}_{2} \mathrm{O}_{5}\left(2,2\right.$ g planta $\left.^{-1}\right), \mathrm{K}_{2} \mathrm{O}\left(10,8 \mathrm{~g} \mathrm{planta}^{-1}\right.$ ano $\left.^{-1}\right) \mathrm{e}$ 
TABELA 2 - Comprimento de folhas após 18 meses de cultivo, diâmetro, comprimento e massa fresca dos frutos sem e com coroa de abacaxizeiro 'Cayenne Champac', sob irrigação, utilizando mudas micropropagadas sem inoculação (controle) e inoculadas de bactéria relacionada a B. cepacia (AB213) e de A. bogorensis (AB219) e adubação nos níveis de $180 \mathrm{~kg} \mathrm{ha}^{-1}$ ano $^{-1}$ e $300 \mathrm{~kg} \mathrm{ha}^{-1}$ ano $^{-1}$ de N, em Pacajus (CE).

\begin{tabular}{|c|c|c|c|c|c|c|c|c|c|c|c|c|}
\hline \multirow{2}{*}{\multicolumn{2}{|c|}{ Tratamentos }} & \multirow{2}{*}{\multicolumn{2}{|c|}{$\begin{array}{c}\text { Comprimento } \\
\text { da folha }\end{array}$}} & \multirow{2}{*}{\multicolumn{2}{|c|}{$\begin{array}{l}\text { Comprimento do } \\
\text { fruto }\end{array}$}} & \multirow{2}{*}{\multicolumn{2}{|c|}{ Diâmetro do fruto }} & \multicolumn{4}{|c|}{ Massa fresca do fruto } & \multirow{3}{*}{$\begin{array}{c}\text { Produção }^{(2)} \\
\text { t ha }^{-1}\end{array}$} \\
\hline & & & & & & & & \multicolumn{2}{|c|}{ Sem coroa } & \multicolumn{2}{|c|}{ Com coroa } & \\
\hline $\mathrm{kg} \mathrm{ha}^{-1} \mathrm{ano}^{-1}$ & Inóculo & $\mathrm{cm}$ & $\mathrm{I}^{(1)}$ & $\mathrm{cm}$ & $\mathrm{I}^{(1)}$ & $\mathrm{cm}$ & $\mathrm{I}^{(1)}$ & $\mathrm{kg}$ & $\mathrm{I}^{(1)}$ & $\mathrm{kg}$ & $\mathrm{I}^{(1)}$ & \\
\hline \multirow[t]{3}{*}{180} & Controle & 52,13 & 0 & 13,62 & 0 & 12,19 & 0 & 1,047 & 0 & 1,300 & 0 & 48,16 \\
\hline & AB213 & 54,45 & 4,5 & 13,81 & 1,4 & 11,88 & $-2,6$ & 1,164 & 11,1 & 1,429 & 9,9 & 52,94 \\
\hline & AB219 & 54,15 & 3,9 & 13,67 & 0,1 & 12,32 & 1,1 & 1,208 & 15,4 & 1,485 & 14,2 & 54,99 \\
\hline \multirow[t]{3}{*}{300} & Controle & 70,80 & 0 & 13,93 & 0 & 12,58 & 0 & 1,342 & 0 & 1,679 & 0 & 62,17 \\
\hline & AB213 & 76,20 & 7,6 & 14,96 & 7,4 & 13,35 & 6,1 & 1,508 & 12,4 & 1,775 & 5,8 & 65,75 \\
\hline & AB219 & 79,43 & 12,2 & 15,72 & 12,9 & 13,68 & 8,8 & 1,602 & 19,4 & 1,968 & 17,3 & 72,90 \\
\hline CV (\%) & & 7,7 & - & 10,4 & - & 5,4 & - & 12,8 & - & 9,2 & - & 9,2 \\
\hline
\end{tabular}

${ }^{(1)}$ Incremento $=\left[100(\mathrm{X}-\mathrm{Y}) \mathrm{Y}^{-1}\right]$, onde $\mathrm{X}$ é planta inoculada de bactéria diazotrófica e $\mathrm{Y}$ a planta-controle para cada nível de $\mathrm{N}$.

${ }^{(2)}$ Equivalente a 37.037 plantas.

óxido silicatado $\left(1,35 \mathrm{~g}\right.$ planta $^{-1}$ ano $\left.^{-1}\right)$, independentemente da inoculação de bactérias diazotróficas na fase de mudas (Tabela 2). Tal adubação propiciou a formação de brotos vigorosos após a colheita dos frutos, favorável à produção na soca ou à formação de mudas no campo. A adubação do abacaxizeiro nos plantios comerciais é geralmente feita no primeiro ano de cultivo. Souza (1999) destacou o maior aproveitamento dos fertilizantes durante a fase vegetativa das plantas e relatou que, de modo geral, eram aplicados, no Brasil, entre 6 e $10 \mathrm{~g} \mathrm{planta}^{-1}$ de N, 1 a $4 \mathrm{~g}$ planta $^{-1}$ de $\mathrm{P}_{2} \mathrm{O}_{5}$ e 4 a $15 \mathrm{~g}_{\text {planta }}{ }^{-1}$ de $\mathrm{K}_{2} \mathrm{O}$. Porém, outras recomendações têm sido feitas para a cultura, podendo chegar a 19,2 $\mathrm{g}_{\text { planta }}{ }^{-1}$ de $\mathrm{N}$ e de $\mathrm{K}_{2} \mathrm{O}$ e 4,8 $\mathrm{g}_{\text {planta }}{ }^{-1}$ de $\mathrm{P}_{2} \mathrm{O}_{5}$ (Spironello \& Furlani, 1997) e até $22 \mathrm{~g}$ planta ${ }^{1}$ de $\mathrm{K}_{2} \mathrm{O}$ (Veloso et al., 2001). Além disso, tem-se recomendado aplicação de micronutrientes na cultura (Souza, 1999).

As plantas não apresentaram sintomas de doença, nem espinhos nas folhas, o que é uma característica cultivar Cayenne Champac. O aparecimento de espinhos nas cultivares de folha lisa, de acordo com Firoozabady \& Gutterson (2003), pode ocorrer em conseqüência do processo de micropropagação. Considerando o curto período na multiplicação in vitro, de aclimatação na casa de vegetação e de cultivo no campo até a colheita de frutos ( 15 a 18 meses, na parcela com maior nível de $\mathrm{N}$ ), verifica-se que o ciclo é de aproximadamente 30 meses. Esse período é considerado curto quando não se têm mudas disponíveis ou se obtém baixo número de rebentos no campo. No grupo Cayenne, o número de brotações que surgem no campo é baixo. Na cultivar Smooth Cayenne, de acordo com Choairy et al. (1994), são formados menos de cinco rebentos por planta.

Aos 18 meses de cultivo no campo, foram colhidos mais frutos na parcela de maior nível de $\mathrm{N}$, enquanto, na de menor nível do elemento, o pico de colheita ocorreu após 21 meses do plantio. Este atraso deveuse à aplicação mais tardia do tratamento de indução floral. O período entre o lançamento de inflorescências e a colheita foi relativamente curto (quatro meses), provavelmente devido à elevada temperatura do ar, ao período de insolação (Tabela 1) e à irrigação das plantas. Souza et al. (2002), utilizando mudas tradicionais da cultivar Pérola e o sistema de irrigação por aspersão, observaram inflorescências após 10 meses do plantio, porém a colheita foi realizada aos 16 meses de cultivo no campo. No sistema de sequeiro, o período até o florescimento é geralmente maior. Spironello et al. (1997a, b) observaram indução natural da cultivar Smooth Cayenne, em São Paulo, após 12 meses do plantio de mudas obtidas no campo. A indução com um ano do plantio também é vantajosa para a cultivar (Choairy et al., 1994) e SNG-3, cultivar de padrão semelhante ao Smooth Cayenne (Gondim \& Azevedo, 2002), em termos de rendimento, redução da acidez e aumento do teor de sólidos solúveis totais, comparado a períodos mais curtos na indução da floração.

$\mathrm{O}$ aspecto vigoroso dos abacaxizeiros pode ser notado pelo comprimento das folhas medianas e pelas características dos frutos no nível maior de N, em comparação com o nível menor do elemento (Tabela 2). Com adubação nitrogenada na dose maior, obteve-se incremento equivalente a $14.910 \mathrm{~kg} \mathrm{ha}^{-1}(28,6 \%)$ na massa fresca dos frutos com coroa. Obteve-se um número maior de frutos mais pesados (Figura 1). Para cada quilograma do $\mathrm{N}$ fornecido, obteve-se incremento de 124,25 $\mathrm{kg} \mathrm{ha}^{-1}$ na massa fresca dos frutos com coroa, dentro dos níveis de $\mathrm{N}$ utilizados. Isso também deve ser considerado no cultivo do abacaxizeiro.

Houve aumento significativo na massa fresca dos frutos sem coroa, correspondendo a $19,4 \%$ ou $9.630 \mathrm{~kg}$, e na dos frutos com coroa, de $17,3 \%$ ou $10.730 \mathrm{~kg} \mathrm{ha}^{-1}$, quando foram utilizadas mudas inoculadas de A. bogorensis AB219, em comparação com mudas sem inoculação bacteriana, no nível maior de N (Tabela 2). Tais quantidades foram baseadas na densidade de 37.037 plantas ha- ${ }^{-1}$, e os níveis de significância foram $9,5 \%$ e 4,3\% de probabilidade no teste $t$, respectivamente (Tabela 3). Em presença do AB219, obteve-se também maior número de frutos do tipo $\mathrm{A}(>1,5 \mathrm{~kg})$, em relação às plantas sem inoculação e inoculadas do

TABELA 3 - Estimativa de diferença e o valor $p$ para o comprimento de folhas após 18 meses de cultivo, o diâmetro, o comprimento e a massa fresca dos frutos sem e com coroa de abacaxizeiro 'Cayenne Champac', sob irrigação, entre médias dos contrastes com mudas micropropagadas sem inoculação (controle) e inoculadas de bactéria relacionada a B. cepacia (AB213) e de A. bogorensis (AB219) dentro dos níveis de $180 \mathrm{~kg} \mathrm{ha}^{-1} \mathrm{ano}^{-1}$ e $300 \mathrm{~kg} \mathrm{ha}^{-1} \mathrm{ano}^{-1}$ de N, em Pacajus (CE).

\begin{tabular}{|c|c|c|c|c|c|c|c|c|c|c|c|}
\hline \multirow{2}{*}{\multicolumn{2}{|c|}{ Tratamentos }} & \multirow{2}{*}{\multicolumn{2}{|c|}{$\begin{array}{l}\text { Comprimento } \\
\text { da folha }\end{array}$}} & \multirow{2}{*}{\multicolumn{2}{|c|}{$\begin{array}{l}\text { Comprimento do } \\
\text { fruto }\end{array}$}} & \multirow{2}{*}{\multicolumn{2}{|c|}{ Diâmetro do fruto }} & \multicolumn{4}{|c|}{ Massa fresca do fruto } \\
\hline & & & & & & & & \multicolumn{2}{|c|}{ Sem coroa } & \multicolumn{2}{|c|}{ Com coroa } \\
\hline $\mathrm{kg} \mathrm{ha}^{-1}$ ano $^{-1}$ & Contrastes & $\mathrm{cm}$ & $p^{(1)}$ & $\mathrm{cm}$ & $p^{(1)}$ & $\mathrm{cm}$ & $p^{(1)}$ & $\mathrm{kg}$ & $p^{(1)}$ & $\mathrm{kg}$ & $p^{(1)}$ \\
\hline \multirow[t]{3}{*}{180} & AB213 vs. Controle & 2,32 & 0,583 & 0,19 & 0,879 & $-0,31$ & 0,599 & 0,117 & 0,419 & 0,129 & 0,316 \\
\hline & AB219 vs. Controle & 2,01 & 0,635 & 0,06 & 0,962 & 0,13 & 0,817 & 0,161 & 0,274 & 0,184 & 0,165 \\
\hline & AB213 vs. AB219 & 0,31 & 0,942 & 0,13 & 0,917 & $-0,45$ & 0,446 & $-0,040$ & 0,755 & $\begin{array}{c}- \\
0,055\end{array}$ & 0,659 \\
\hline \multirow[t]{5}{*}{300} & AB213 vs. Controle & 5,40 & 0,222 & 1,02 & 0,421 & 0,77 & 0,202 & 0,166 & 0,259 & 0,096 & 0,446 \\
\hline & AB219 vs. Controle & 8,63 & 0,067 & 1,79 & 0,177 & 1,11 & 0,082 & 0,260 & 0,095 & 0,290 & 0,043 \\
\hline & AB213 vs. AB219 & $-3,23$ & 0,452 & - & 0,544 & - & 0,566 & - & 0,514 & $-0,193$ & 0,148 \\
\hline & & & & 0,77 & & 0,33 & & 0,094 & & & \\
\hline & rro padrão & 4,08 & - & 1,21 & - & 0,56 & - & 0,14 & - & 0,12 & - \\
\hline
\end{tabular}

(1) Probabilidade de erro associado ao teste t do contraste 


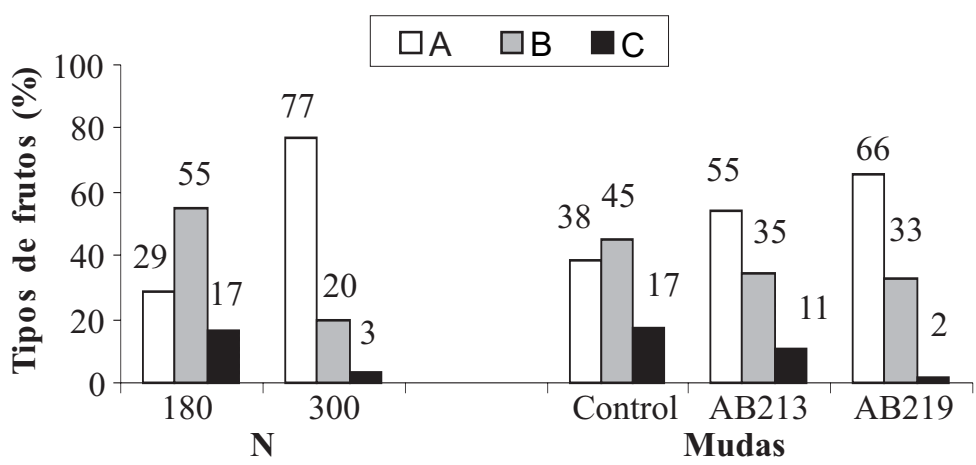

FIGURA 1- Número médio de frutos dos tipos A (> 1,5 kg), B (1,2 a 1,5 $\mathrm{kg})$ e $\mathrm{C}(<1,2 \mathrm{~kg})$ de abacaxizeiro 'Cayenne Champac', colhido nas parcelas com adubação nos níveis de $180 \mathrm{~kg}$ ha $^{-1}$ ano $^{-1}$ e $300 \mathrm{~kg} \mathrm{ha}^{-1}$ ano $^{-1}$ de $\mathrm{N}$, e nas subparcelas, utilizando mudas micropropagadas sem inoculação (controles) e com inoculação de bactéria relacionada a $B$. cepacia (AB213) e de bactéria A. bogorensis (AB219), em Pacajus (CE).

AB213 (Figura 1). Além disso, houve aumento significativo no comprimento das folhas pelo teste $t$ (probabilidade de 6,7 \%), quando da inoculação do AB219 nas mudas micropropagadas e da adubação nitrogenada, sugerindo vantagem da técnica.

O incremento na produção do abacaxizeiro foi menor com mudas inoculadas do AB213, comparado ao tratamento com o AB219 (Tabela 2). O incremento na massa fresca dos frutos com coroa chegou a $9,9 \%$ no menor nível de $\mathrm{N}$, sendo que a diferença em relação ao controle correspondeu a $4.780 \mathrm{~kg} \mathrm{ha}^{-1}$. Por sua vez, o contraste entre plantas inoculadas do AB213 vs. controle não atingiu nível satisfatório de significância no teste $\mathrm{t}(p=0,165)$ (Tabelas 3$)$. As contribuições diferenciadas dos isolados de bactérias utilizadas sobre a produção da cultivar Cayenne Champac (Tabela 2) se somam às observações feitas para mudas das cultivares Pérola e Smooth Cayenne micropropagadas, quando inoculadas dos mesmos isolados (Weber et al., 2003a), e para mudas da cultivar Cayenne Champac inoculadas do AB219 (Weber et al., 2003b), permitindo sugerir que é vantagem inocular bactérias diazotróficas em mudas micropropagadas do abacaxizeiro.

Os menores incrementos sobre o crescimento e a produção dos abacaxizeiros proporcionados pelos isolados das bactérias no menor nível de $\mathrm{N}$ eram inesperados (Tabela 2). Isso dá idéia de que não houve compensação do adubo nitrogenado pela associação das plantas com os isolados AB213 e AB219. Mesmo assim, não se pode descartar a hipótese da fixação biológica do $\mathrm{N}_{2}$ na cultura do abacaxizeiro. Esse processo tem sido evidenciado na cultura da cana-de-açúcar (Boddey et al., 2003), plantas de arroz (Baldani et al., 2000) e outras gramíneas (Reis et al., 2000; Dobbelaere et al., 2003). Acredita-se que o abacaxizeiro cv. Cayenne Champac beneficiou-se mais da produção de hormônios, pelas bactérias. A produção de hormônios foi observada com culturas de bactérias dos gêneros Burkholderia (Malik et al., 1997), Herbaspirillum, Azospirillum (Radwan et al., 2002), e esse fato, de acordo com Dobbelaere et al. (2003), poderia também explicar benefícios em várias culturas.

A presença das bactérias diazotróficas foi confirmada nas raízes e nos caules dos abacaxizeiros, após 18 meses do plantio (Figuras 2 e 3 ). As maiores populações de bactérias foram detectadas nas raízes e nos abacaxizeiros inoculados do AB213. Vale destacar que a maior população de bactérias não foi acompanhada da maior produção dos abacaxizeiros inoculados do AB213 (Tabela 2), sugerindo que o AB219 foi mais efetivo no abacaxizeiro. As populações de bactérias diazotróficas detectadas nas amostras esterilizadas de raízes $\left(10^{4}\right.$ a $10^{6}$ células $\mathrm{g}^{-1}$ de massa fresca)

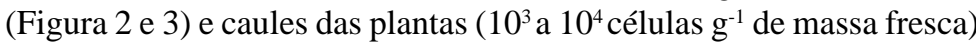
(Figura 2) foram semelhantes, em densidade, às observadas nos abacaxizeiros de cultivos na Bahia e no Rio de Janeiro (Weber et al., 1999). Densidades populacionais semelhantes têm sido apresentadas para Gluconoacetobacter diazotrophicus em cana-de-açúcar (Reis et al., 2000), cultura que se beneficia da fixação biológica. Tal espécie de bactérias também tem sido isolada de abacaxizeiros no México (TapiaHernández et al., 2000), mas não relatada em abacaxizais no Brasil (Weber et al., 1999).

No estudo em pauta, não se deu importância ao acúmulo de nutrientes pelas plantas nem à identificação dos isolados de bactérias associados às mesmas e, sim, aos benefícios da associação sobre a produção de frutas. Entretanto, trabalhos poderiam ser realizados para avaliar a absorção de nutrientes pelas plantas e a persistência de isolados de bactérias ao longo do ciclo do abacaxizeiro.

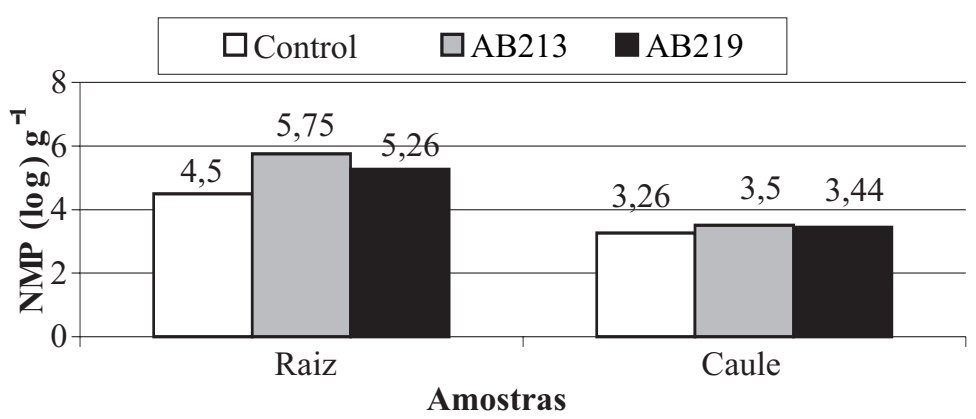

FIGURA 2 - Número mais provável (NMP) de bactérias diazotróficas por grama de matéria fresca das raízes e do caule de abacaxizeiro 'Cayenne Champac', após 18 meses de cultivo sob irrigação, utilizando mudas micropropagadas sem inoculação (Control) e inoculadas de bactéria diazotrófica relacionada a B. cepacia (AB213) e de A. bogorensis (AB219) e adubadas no nível de $\mathrm{N} 100$ (300 kg ha-1 ano $\left.{ }^{-1}\right)$, em Pacajus (CE).

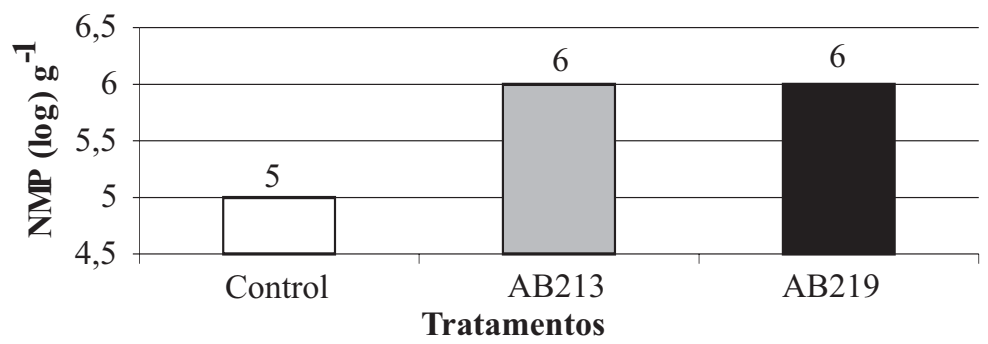

FIGURA 3 - Número mais provável (NMP) de bactérias diazotróficas por grama de matéria fresca das raízes e do caule de abacaxizeiro 'Cayenne Champac', após 18 meses de cultivo sob irrigação, utilizando mudas micropropagadas sem inoculação (Control) e inoculadas de bactéria diazotrófica relacionada a $B$. cepacia $(\mathrm{AB} 213)$ e de $A$. bogorensis (AB219), e adubadas no nível de $\mathrm{N} 60$ (180 $\left.\mathrm{kg} \mathrm{ha}^{-1} \mathrm{ano}^{-1}\right)$, em Pacajus (CE).

\section{CONCLUSÕES}

1. O abacaxizeiro 'Cayenne Champac' teve bom desempenho sob irrigação no Argissolo em Pacajus, Estado do Ceará, quando adubado com $8,1 \mathrm{~g}$ por planta por ano de N, 2,2 g por planta de $\mathrm{P}_{2} \mathrm{O}_{5}, 10,8$ g por planta por ano de $\mathrm{K}_{2} \mathrm{O}$ e 1,35 g por planta por ano de óxido silicatado, contendo 9,2\% de zinco, 2,2\% de boro, 0,8\% de cobre, 3,7 \% de ferro, $3,4 \%$ de manganês e $0,1 \%$ de molibdênio.

2. Cada quilograma de $\mathrm{N}$ fornecido propiciou incremento equivalente a $124,3 \mathrm{~kg} \mathrm{ha}^{-1}$ de frutos com coroa, na faixa de 4,86 a 8,1 $\mathrm{g} \mathrm{de}$ $\mathrm{N}$ por planta por ano.

3. A inoculação de A. bogorensis AB219 nas mudas micropropagadas aumentou em 19,4 e 17,3\% a massa fresca dos frutos sem e com coroa, em relação às plantas não inoculadas de bactérias, na dose de $8,1 \mathrm{~g}$ de $\mathrm{N}$ por planta por ano.

4. A bactéria relacionada a B. cepacia AB213 aumentou em até $9,9 \%$ a massa fresca dos frutos com coroa, em relação às plantascontrole, na dose de $4,86 \mathrm{~g}$ de $\mathrm{N}$ por planta por ano. 


\section{AGRADECIMENTOS}

Os autores agradecem à pesquisadora Aline de Holanda Nunes Maia da Embrapa Meio Ambiente, pelas sugestões na análise estatística.

\section{REFERÊNCIAS}

AGRIANUAL 2001: anuário da agricultura brasileira. São Paulo: FNP Consultoria e Comércio, 2002. 536p.

BALDANI, V.L.D.; BALDANI, J.I.; DÖBEREINER, J. Inoculation of rice plants with the endophytic diazotrophs Herbaspirillum seropedicae and Burkholderia spp. Biology and Fertility of Soils, Berlin, v.30, p.485-491, 2000.

BODDEY, R.M; URQUIAGA, S.; ALVES, B.J.R.; REIS, V.M. Endophytic nitrogen fixation in sugarcane: present knowledge and future applications. Plant and Soil, Dordrecht, v.252, p.139-149, 2003.

CHOAIRY, S.A.; FERNANDES, P.D.; OLIVEIRA, E.F. de. Estudo de época de plantio, peso de muda e idade de indução floral em abacaxi cv. Smooth Cayenne. Pesquisa Agropecuária Brasileira, Brasília, v.29, n.1, p.63-71, jan. 1994.

DÖBEREINER, J.; BALDANI, V.L.D.; BALDANI, J.I. Como isolar e identificar bactérias diazotróficas de plantas não-leguminosas. Brasília: Embrapa-SPI/Embrapa-CNPAB, 1995.60p.

DOBBELAERE, S.; VANDERLEYDEN, J. OKON, Y. Plant growthpromoting effects of diazotrophs in the rhizosphere. Critical Reviews in Plant Sciences, Boca Raton, v.22, n.2, p.107-149, 2003.

FAO (Roma-Itália). FAOSTAT Agriculture data. Disponível em: <http:/ /apps.fao.org/page/form?collection=Production.Crops.Primary $\&$ Domain $=$ Production $\&$ servlet $=1 \&$ language $=E N \&$ hostname $=$ apps.fao.org\&version=default $>$. Acesso em: 18 nov. 2003.

FIROOZABADY, E.; GUTTERSON, N. Cost-effective in vitro propagation methods for pineapple. Plant Cell Reports, New York, v.21, n.9, p.844-850, June 2003.

GONDIM, T.M. de S.; AZEVEDO, F.F. de. Diferenciação floral do abacaxizeiro cv. SNG-3 em função da idade da planta e da aplicação do carbureto de cálcio. Revista Brasileira de Fruticultura, Jaboticabal, v.24, n.2, p.420-425, 2002.

MALIK, K.A.; BILAL, R.; MEHNAZ, S.; RASUL, G.; MIRSA, M.S.; ALI, M.S. Association of nitrogen-fixing, pant-growth-promoting rhizobacteria (PGPR) with kallar grass and rice. Plant and Soil, Dordrecht, v.194, p.37-44, 1997.

MONTGOMERY, D.C. Design and analysis of experiments. 3.ed. New York: John Wiley, 1991.649p.

MURASHIGE, T.; SKOOG, F.A. revised medium for rapid growth and bioassays with tabacco tissue cultures. Physiologia Plantarum, Copenhagen, v.26, p.473-497, 1962.

RADWAN, T.; MOHAMED, Z.K.; REIS, V.M. Production of indole-3acetic acid by straisn of Azospirillum and Herbaspirillum spp. Symbiosis, Rehovold, v.32, n.1, p.39-53, 2002.

REINHARDT, D. H.; SOUZA, J. da S. Pineapple industry and research in Brazil. Acta Horticulturae, Wageningen, n.529, p.57-71, 2000.

REIS, V.M.; BALDANI, J.I.; BALDANI, V.L.D., DÖBEREINER, J. Biological dinitrogen fixation in graminea and palm tree. Critical Reviews in Plant Sciences, Boca Raton, v.19, p.227-247, 2000.

SANTANA, L.L. deA.; REINHARDT, D.H.; CUNHA, G.A.P. da; CALDAS, R.C. Altas densidades de plantio da cultura do abacaxi cv Smooth Cayenne, sob condições de sequeiro. Revista Brasileira de Fruticultura, Jaboticabal, v.23, n.2, p.353-358, ago. 2001

SANTOS, BIVANILDAA., ZAMBOLIM, LAÉRCIO, VENTURA, JOSÉ A. et al. Severidade de isolados de Fusarium subglutinans f. sp. ananas sensíveis e resistentes ao benomyl, em abacaxizeiro. Fitopatologia Brasileira, Brasília, v.27, n.1, p.101-103, jan./fev. 2002.
SEAGRI-CE. (Secretaria de Agricultura Irrigada do Ceará. O agronegócio da agricultura irrigada no Estado do Ceará (1999 a 2003). Disponível em: <http://www.seagri.ce.gov.br/siga/Informacoes_ gerais_agricIrrigada_1999_2003_frutal.pdf $>$. Acesso em: 30 out. 2003.

SILVA, F.C. Manual de análises químicas de solos, plantas e fertilizantes. Brasília: Embrapa-SCT/Embrapa-CNPS/Embrapa-CNPTIA, 1999. 370p.

SOUZA, L.F. da S. Correção da acidez e adubação. In: CUNHA, G.A.P da; CABRAL, J.R.S.; SOUZA, L.F. da S. (Org.) O abacaxizeiro: cultivo, agroindústria e economia. Brasília: Embrapa Comunicação e Transferência de Tecnologia, 1999. p.169-202.

SOUZA, L.F. da S.; ALMEIDA, O.A.; CALDAS, R.C.; REINHARDT, D.H. Effect of soil moisture and fertilization on Pérola pineapple in coastal tabland areas of Brazil. Tropical Agriculture, London, v.79, n.2, p.83-87, 2002.

SPIRONELLO, A.; FURLANI, P.R. Abacaxi. In: RAIJ, B. van; CANTARELLA, H.; QUAGGIO, J.A.; FURLANI, A.M.C. (Ed.). Recomendações de adubação e calagem para o estado de São Paulo. 2.ed.rev.atual. Campinas: Instituto Agronômico: FUNDAG, 1997. p.128. (Boletim Técnico, 100)

SPIRONELLO, A.; BORTOLETTO, N.; SIGRIST, J.M.M.; NAGAI, V. Avaliação agrotecnológica e do ciclo de variedades de abacaxizeiro, em duas densidades, em Votuporanga (SP). Bragantia, Campinas, v.56, n.2, p.343-355, 1997a.

SPIRONELLO, A.; NAGAI, V.; TEOFILO SOBRINHO, J.; TEIXEIRA, L.A.J.; SICRIST, J.M.M. Avaliação agrotecnológica de variedades de abacaxizeiro, conforme os tipos de muda, em Cordeirópolis (SP). Bragantia, Campinas, v.56, n.2, p.333-342, 1997b,

TAPIA-HERNÁNDEZ, A.; BUSTILLOS-CRISTALES, M.R.; JIMENEZSALGADO, T.; CABALLERO-MELLADO, J.; FUENTES-RAMIRES, L.E. Natural endophytic occurrence of Acetobacter diazotrophicus in pineapple plants. Microbial Ecology, New York, v.39, p.49-555, 2000.

TEIXEIRA, J.B.; CRUZ, A.R.R.; FERREIRA, F.R.; CABRAL, J.R. Biotecnologia aplicada à produção de mudas: produção de mudas micropropagadas de abacaxi. Biotecnologia-Ciência e Desenvolvimento, Brasília, v.3, p.42-47, 2001

VELOSO, C.A.C.; OEIRAS, A.H.L.; CARVALHO, E.J.M.; SOUZA, F.R.S. de. Resposta do abacaxizeiro à adição de nitrogênio, potássio e calcário em Latossolo Amarelo do Nordeste paraense. Revista Brasileira de Fruticultura, Jaboticabal, v.23, n.2, p.396-402, ago. 2001.

WEBER, O.B.; CORREIA, D.; ROCHA, M.W..;ALVEZ, G.C.; OLIVEIRA, E.M. de; SÁ, E.G. Resposta de plantas micropropagadas de abacaxizeiro à inoculação de bactérias diazotróficas em casa de vegetação. Pesquisa Agropecuária Brasileira, Brasília, 2003a. (PAB 3174, submetido).

WEBER, O.B.; CORREIA, D.; SILVEIRA, M.R.S.; CRISÓSTOMO, L.A.; OLIVEIRA, E.M. de; SÁ, E.G. Efeito de bactéria diazotrófica em mudas micropropagadas de abacaxizeiros Cayenne Champac em diferentes substratos. Pesquisa Agropecuária Brasileira, Brasília, v.38, p.689696, jun. 2003b.

WEBER, O.B.; BALDANI, V.L.D.; TEIXEIRA, K.R.S.; KIRCHHOF, G.; BALDANI, J.I.; DOBEREINER, J. Isolation and characterization of diazotrophic bacteria from banana and pineapple plants. Plant and Soil, Dordrecht, v.210, p.103-113, 1999. 